\title{
Co-creating transdisciplinary global change research agendas in Finland
}

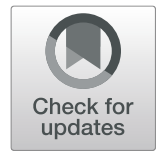

Kaisa Matschoss ${ }^{*^{*}}$, Maria Pietilä ${ }^{1}$, Mikko Rask ${ }^{1}$ and Tanja Suni ${ }^{2}$

\begin{abstract}
Co-creation principles have become prominent in the scientific disciplines that aim to respond to global sustainability challenges especially in the global south. This paper analyses a co-creation pilot of global change research in the novel context of a Nordic country, Finland. The pilot was organised to learn how to create a future agenda for a complex and transdisciplinary research field of global change. This paper analyses its conceptualisation in Finland, how did the series of engagement events increase the capacities of participants and how did the process contribute to a change towards a new, societally responsible way of co-creating global change research. The study found that co-creation suits well for the translation of important societal questions into global research agendas and for networking actors to cocreation activities. Based on the study, we argue that co-creation offers a socially acceptable approach to address socially critical topics to design transdisciplinary social and sustainability research.
\end{abstract}

Keywords: Co-creation „F Future Earth "Global change research" Global North", Sustainability "Transdisciplinarity

\section{Introduction}

Multiple fields and sectors in modern societies could benefit from co-creation of ideas, solutions and products for sustainability transition (e.g. [1-3]). In the field of scientific research, co-creation has been most visible in the field of innovation studies, for example in the attempts to commercialise research by producing patents, inventions, new products and business partnerships (e.g. [4]). It has also found applications in futures research [5-7]. Recently, along with global environmental issues, co-creation principles have become prominent also in the scientific disciplines that aim to respond to global sustainability challenges [7-9]. Emmenegger et al. [10] have recognised the need for integrative research initiatives as scientific knowledge targets various social aims and is inherently situated within networks of social and institutional power. This paper examines the process of co-creation for global change research in the national context of Finland.

In the field of global change research, complex sustainability problems, such as water scarcity, epidemics and climate change, especially in the global south require new ways of knowledge production and decision-making (e.g. [9-13]). While the focus of global change research may have been in the global south, research on urgent future sustainability challenges in terms of global change is called for in the northern context as well. Setting cocreation processes on a national level can bring forth topics relevant especially in that country, culture or area, which is why targeting global change research from a national perspective is also important to deepen the understanding of global change as a phenomenon.

Tackling complex sustainability challenges requires input from different communities of knowledge, disciplines and societal stakeholders (e.g. $[6,14,15])$. Co-creation as a transdisciplinary and participatory research approach underlines the necessity to collaborate with a variety of societal stakeholders to design solutions and bring about sustainable transformation in the society (e.g. $[5,16])$. Therefore, sustainability and global change research are expected to result in greater societal acceptance and impact if different phases of research processes engage stakeholders and citizens in co-creating research agendas and questions, analysing problems and co-producing solutions, and in disseminating the results (e.g. $[10,14])$.

\footnotetext{
* Correspondence: kaisa.matschoss@helsinki.fi

${ }^{1}$ University of Helsinki, Unioninkatu 40 C, P.O.Box 24, 00014 Helsinki, Finland Full list of author information is available at the end of the article
} 
This paper examines a case of how a series of multiactor events served to engage a variety of stakeholders in co-creating societally relevant global change research in Finland, and how it opened up the agenda-setting stage for stakeholders and wider audiences. The research draws on a case study of an experimental initiative of the pilot for global change research coordinated by Future Earth Finland (FEF). The pilot is one of the few applications of the co-creation approach for global change research in Finland. Our analysis contributes to a better understanding of how global change research is defined in a co-creative setting in this novel context of the global north. Global change research has been previously addressed for example in the FIGHARE programme ${ }^{1}$ in 1999-2002, that focused on studying the underlying causes and impacts of global change at different times and regions and by analysing and predicting its environmental and socio-economic impacts.

There have been prior co-creation events organised for setting research agendas in Finland. However, events organised for diverse kinds of actors in addition to the research community with an emphasis on global change research are not frequent. This pilot presents a case of a sequel of consecutive events, where later events built on the previous ones implying a strong commitment to a long-term development initiative aiming to pilot a more permanent mode of operation. A more detailed description of the co-creation process is given in Fig. 1.

The two-round iterative approach worked as an effective funnelling mechanism in the overall research agenda definition and prioritisation process. At the event level, facilitated small group discussions had a crucial role because they allowed different disciplinary and nondisciplinary perspectives to gain ground equally. Yet, another important tool was an on-line voting tool (Presemo) that was used to make a quick prioritisation of the research topics proposed.

In this paper, we present the results of our analysis on a pilot for the co-creation for global change research for setting a future research agenda. In the next section, we describe key ideas of participatory and transdisciplinary research in relation to sustainability global change research. The third section positions our examination on global change research in a case study research frame and presents our research data. The fourth section highlights our results in terms of conceptualisation, capacities and continuity. The last section discusses and concludes our findings showing that the studied

\footnotetext{
${ }^{1}$ More information on the FIGHARE programme: https://www.aka.fi/ en/research-and-science-policy/academy-programmes/completedprogrammes/figare-finnish-global-change-research-programme-1999-2 $002 /$
}

approach is suitable for setting a future research agenda for transdisciplinary global change research.

\section{Transdisciplinary and participatory sustainability research}

This section reviews the principles of transdisciplinary and participatory research. The key elements of sustainability science are collaboration among different disciplines of science and involvement of actors outside academia in the research projects to co-design solutions to real-world and wicked problems [17]. Sustainability science approach transcends disciplinary boundaries as well as boundaries between science and society. According to Lang et al. [16], the characteristics of such a transdisciplinary research approach include input from different communities of knowledge and disciplines to ensure that essential knowledge from different actor groups relevant to the addressed societal challenge is incorporated. In addition, transdisciplinary research pursues to move from mere descriptive aims towards providing guidance and intervention strategies that lead towards real transformation in society [16]. Furthermore, it is expected that collaboration with stakeholders and citizens increases legitimacy and ownership of research projects and their results, and motivates the actors to take on transformative action in society [18].

Scholars on sustainability science have recognised the key challenges for conducting transdisciplinary sustainability research and the main pitfalls and trade-offs relating to adequate financial resource base and practical and interpersonal expertise (e.g. [16, 19-22]). Our study case aimed to overcome these challenges by supporting and strengthening transdisciplinary and multi-actor research collaboration. The FEF created an institutional forum on global change with the explorative co-creation concept providing support and training for various stakeholder groups to co-design research priorities and to co-create projects and project proposals for funding and research questions.

The co-creation experiment that we examine attempted to widely engage various actors and stakeholders to address future challenges emerging from global change. To that end, a process of multi-actor engagement events in the context of global change research was explored and developed by the organisers from FEF and the research team. The analysis contributes, in particular, to discussions on relevant models of sectoral and scientific integration in global change research [9].

\section{Research frame of the case study on global change research}

This section presents the analysis approach utilised in the study. We describe the case on the multi-actor events on global change, with the reasons behind the 


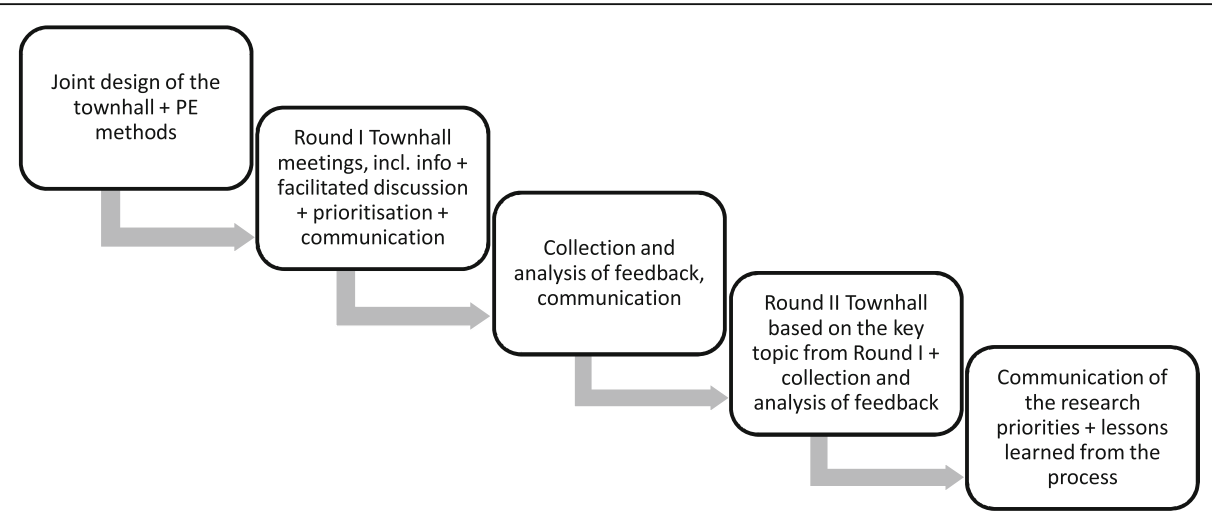

Fig. 1 The main steps of the co-creation process

experiment and its implementation. We also present the data that was used in the analysis of this case study.

\section{Analysis approach}

Our research frame is a case study approach [23]. We utilise an analysis model created based on an analysis of factors in a sample of international public engagement $(\mathrm{PE})$ initiatives that contributed to systemic change (see for more information [24]), such as the co-creation pilot examined in this paper. The model builds on two factors: structural components including conceptualisation, new competences, new solutions and demonstrations, and capacities of dynamic governance that are generally developed through innovative PE processes [24].

Considering that the pilot on global change research was mostly targeted at the design and agenda-setting stage, FEF reasoned that neither the development of new solutions nor demonstrating them be as relevant as conceptualisation and mobilisation of new competences. The FEF also recognised that the role of continuity was emphasised throughout the objectives of the pilot. Resulting from these observations, the case study focused on the attention on the following three aspects of systemic change: conceptualisation, capacities and continuity in co-creation activities. The analysis approach of this study and its relation to the research questions is depicted in Fig. 2.

As Fig. 2 suggests, the object of analysis was the cocreation activities and their outcomes organised under the pilot of global change research frame. The techniques of analysing the experiences from the pilot included deductive (theoretical) and inductive (grounded) content analysis (e.g. $[25,26])$. We examined how the experimental approach of co-designing research in a multi-actor engagement activity contributed to increase understanding of how global change research is understood in a cocreative setting in the Finnish context (RQ1). We also analysed what new capacities were introduced by involving scientific and non-scientific experts to deliberate on global change research issues (RQ2). Finally, we identified different types of continuities that were created to support network building and co-creation of global change research (RQ3).

\section{Case description: pilot of global change research}

In this case description, we first present the rationale for launching the pilot and the main actors of the pilot. In the second section, we introduce its implementation. In addition, we discuss the challenges and problems identified in the implementation.

\section{Motivation of the pilot on global change research by Future Earth Finland}

The main organiser of the pilot, Future Earth Finland (FEF), serves as a national committee for Future Earth, which is an international research programme initiated in 2012 [27]. Currently, it operates under the Science and Technology Alliance for Global Sustainability network $^{2}$. Future Earth brings together natural and social sciences to work towards integrative global change science and solutions-oriented research that engages governments, civil society, research funders, and the private sector in the co-creation of research $[9,28]$.

The rationale for launching the international organisation, Future Earth, and its national platforms, stems from the pressures emerging from large-scale societal

${ }^{2}$ The Science and Technology Alliance for Global Sustainability, http:// www.stalliance.org/. 
challenges that transcend boundaries of traditional academic fields. The Finnish national committee was founded in May 2014. Its aim was firstly to create an interface between research, decision-making, business, and civil society. In addition, this interface would be used to jointly define priorities for global change research and to co-create global change research questions and projects together with researchers and other stakeholders in Finland. FEF began its activities by forming a network for researchers and other stakeholders with the concrete aim to facilitate and initiate transdisciplinary, solutions-oriented research projects and products. The motivation in launching the studied pilot was the need to explore the concept of global change and its significance in Finland and to discuss the potential for organising new kind of transdisciplinary research to respond to the identified problems that are described in the section for results.

FEF realised that a change in research culture related to global change and sustainability questions would be necessary. The selected mechanism was multi-actor engagement in a series of events that inherently works in a way designed to promote such a change because the events act as a platform for connecting various actors in the global change research context. FEF recognised that the actors relevant to the co-creation of global change research are very diverse, including producers, users, stakeholders, citizens and enablers of research. Moreover, it is understood that although researchers have the main responsibility for research, other societal actors can bring invaluable comprehensive knowledge, networks, resources and sometimes also data that researchers could not access by themselves.

We used the following loose typology or 'map' of the relevant societal actor groups during the process. 'Producers' are the researchers creating knowledge. 'Users' can be identified as the government and funding sectors aiming at solving sustainability challenges. In the pilot case, users were not the objects of the study as in conventional innovation projects; instead, they were equal to the producers and other participants as genuine cocreators of value.

'Stakeholders' are actors who have a particular interest in the research process and results and can include 'producers' and 'users'. 'Citizens' (who do not have a particular, but rather a general interest towards the global change research agenda) point out to relevant questions from the laypeople perspective and ensure the societal acceptability of the research. The 'enablers' are companies or organisations that provide supportive technology, virtual or physical space, and other necessary resources to the use of participants. In this case, the boundary organisation facilitating the operation of the pilot, FEF, was the enabler.
The FEF secretariat acted as an interaction partner in research projects and coordinated the communication and interaction with the stakeholders. This role as the key enabler is different from the conventional model of a project manager in controlling the resources and schedules. The participants in a pilot of global change research joined the co-creation work on a voluntary basis and their motivation might weaken or change during the course of the work. Thus, the key enabler's role was foremost to motivate potential participants to join the events and to participate actively.

\section{Implementation of the pilot}

In this pilot, a process of several consecutive events was introduced to provide a new forum for the co-creation activities among a heterogeneous group of participants. The key problems identified in the FEF operation, the problems of (1) conceptualisation; (2) capacities such as contacts and skills; and (3) continuity, such as resources and merits, were tackled by means of a three-tier pilot.

The first part of the pilot targeted the broadness of the global change as a phenomenon from the Finnish perspective and the different ways transdisciplinary research can influence the society. Its mode of operation included the creation of interaction spaces through seminars with brief plenary talks outlining background and state-ofthe-art of the issues followed by small-group discussions to explore the different viewpoints of the diverse participants. These events included producers, users, stakeholders, and citizens (the 2nd event). The main events were the 'Future Earth Townhall' event in Helsinki in May 2015 and the 'Lifetime of a Sustainable City' event in Tampere in September 2015 [29]. The name of the first event (Townhall meeting) refers to a widely known public engagement method of organising large scale events open to all citizens, although in this pilot case the event was organised in a much smaller scale.

The majority of the participants in the two larger-scale events (c. 60 in the 1 st round, c. 40 in the 2 nd round) came from Finnish universities, universities of applied sciences, and public research institutes. The researchers represented both natural sciences and social sciences in a variety of fields, such as forest sciences, environmental sciences, geography, consumer economics, and environmental engineering. Other participants represented sectoral ministries, non-governmental organisations, interest groups, companies, municipalities, and research funders. For the second event, there was a special focus on attracting more participants from the private sector.

In the first event, the participants identified the role of cities as crucial in tackling the challenges of global change: many sustainability questions are linked to cities and urban areas. Due to the emergence of this topic, the second large-scale event focused on creating sustainable 
cities. The overall aim was to collectively deliberate on ideas for potential joint projects on sustainable cities. After the second event, the co-created joint proposals were presented to the most important research funders in Finland related to global change and urban development. The impact of the co-creation pilot thus includes the design of a number of research proposals for the Strategic Research Council of the Academy of Finland and the realisation of the project "Towards Water-Smart Circular Economy" funded by the Nessling Foundation.

The second purpose of the pilot was to increase the capacities of the participants. This included for example support to organisational and individual abilities that contribute to more effective research governance in order to handle issues in a rapidly changing environment that requires continuous adjustment of policies and programmes [30]. Rask et al. [24] have identified anticipation, reflection, transdisciplinarity and continuity ${ }^{3}$ as such core capacities. Additional capacities include raising public awareness, building civic and professional competence and initiation of action. For the development of capacities, the pilot aimed at the creation of novel contacts and resources. The pilot included training, networking events, and researcher and stakeholder workshops to plan joint research proposals. Practical examples included:

- Co-design and science communication training events for researchers (several events during 20152016),

- Networking events for researchers and other stakeholders to co-design research proposals for Strategic Research Council's calls in Finland (several events during 2015-2016), and

- Networking events for researchers and stakeholders, especially companies, to design together with the activities of the recently founded Helsinki Institute of Sustainability Science (HELSUS; a network of researchers working on sustainability) (January 2016).

The third purpose of the pilot focused on continuity. It refers to embedding of new activities within existing institutional frameworks and to building bridges

\footnotetext{
${ }^{3}$ Anticipation is defined as the capacity for prospective thinking and acting. This is an important capacity, for example, in the identification and conceptualisation of issues emerging with scientific and technological innovations. In this sense, anticipation is closely linked to 'upstream engagement'. Reflection refers to the capacity to publicly accomplish critical reflective dialogues with relevant stakeholders, who can take the role of the other, develop shared values, and subject their reasoning to public scrutiny. Transdisciplinarity means the capacity of holistic thinking and acting by mobilising knowledge, expertise and other resources across and beyond scientific disciplines. Continuity refers to the continuation of activities [25].
}

between separate interventions. Continuity is needed to balance the accelerated change caused by increasingly dynamic governance actions, such as increasing the number of external stakeholders in the design of academic research agendas. The need for continuity has been recognised in several streams of the scholarly literature. Systemic approaches both in innovation studies (e.g. [31]) and studies of deliberative democracy (e.g. [32]) emphasising the importance of managing institutional interdependences and path dependences that can either support or hinder effective action. Conversely, if discontinuity prevails between activities, this hinders organisational and institutional learning and limits the effectiveness of interventions as there is no accumulation of the effects. As the pilot represented a rupture of traditional ways of defining academic research agendas by expanding the number of external stakeholders, this study aims at understanding the types of continuities that were developed through the pilot experiment process.

\section{Data and its use in the analysis}

The study data consist of the following materials. Publically open material is the documentation of the two engagement events, 'Future Earth Townhall' and the 'Lifetime of a Sustainable City', organised by FEF. The PE2020-project ${ }^{4}$ that co-operated in the organisation of the pilot observed the events. The researchers of the PE2020-project documented and reported the materials produced in the day-long deliberations including semistructured interviews with the organisers and feedback collected from the participants in the events (see a report of Pietilä and Matschoss 2016).

The first co-creation event 'Future Earth Townhall' started with a pre-assignment sent to the participants to receive input on key priorities for future global change research in Finland for the discussions in the meeting.

At the event level, a practical method for stimulating deliberation was to utilise small group discussions. When the participants entered the venue, a public space at the centre of Helsinki, they were directed to groups. The composition of the groups was planned so that a variety of perspectives would prevail (representation of different backgrounds). The $1 \mathrm{~h}$-length discussion aimed to deepen the deliberation on the priorities in global change research from the perspective of Finland. In addition, the groups deliberated which phenomena or actors enable or inhibit sustainable development in Finland. After that, the groups discussed the present conditions of doing global change research in Finland and ideas to alter them. Detailed facilitator instructions

${ }^{4}$ PE2020-project $=$ Public Engagament Innovations for Horizon 2020, www.pe2020.eu 
were prepared prior to the event. All the facilitators took notes during the discussions. After the meeting, FEF secretariat compiled the notes and key points from the pre-assignment into a public summary report, which was sent to all the participants.

Small group discussions were utilised also in the second event organised in Tampere because they had received positive feedback. The second event also used an online tool 'Presemo' with which the participants could vote for the priorities for the most pressing challenges related to sustainable cities. The first part of the discussion concerned the identification of the most pressing challenges related to the topic of sustainable cities. The groups discussed the challenges after which each group formulated three most important challenges for the whole audience to vote. To make sure that the identified challenges were not overlapping, a jury went through the challenges and lumped the overlapping challenges together. After that, the participants were asked to vote for the three most significant challenges with their electronic device. As a result, five challenges with the most votes were selected for further elaboration. The second dataset of this research thus consists of the preassignment of the first event, notes from the small group discussions, summaries, and an evaluation of the two events including participant observation.

In addition, the research data includes observations from other organised smaller events such as co-design and science communication training, networking events for researchers and other stakeholders to design together research proposals and concrete cases, where the FEF secretariat acted as an interaction partner in research projects and coordinated the communication and interaction with the stakeholders.

The co-creation of academic research is a dynamic process that we analysed by studying the different conceptualisations of the participants (RQ1). We found different conceptualisations in the data through reading and coding of the workshop material. For the study of what new capacities were introduced by involving scientific and non-scientific experts to deliberate on global change research issues (RQ2), we focused on observing new insights and ideas that resulted from the interchange between heterogeneous actors and contributed to the next step in the FEF research agenda-setting process. Especially the interview material as well as feedback surveys were analysed to determine the usefulness of the pilot. In the analysis, we applied the model presented in Fig. 2.

In terms of analysing the continuities, a more exploratory approach was decidedly adopted, by focusing on the different forms of institutional and organisational continuities that either supported or threatened the multi-actor engagement process (RQ3). We used the interview and participant observation material to find answers to the question. In the next section, we present the results of the analysis of the pilot in the co-creation of global change research.

\section{Analysis of the outcomes of a pilot for the co- creation for global change research}

In this chapter, we discuss each research question in a separate section. First, we highlight the particular challenges and problems identified during the research that relate to the topic of global change research and what it means in the Finnish context. Second, we examine how the pilot introduced new co-creation practices of global change research agendas in Finland. Third, we look at the advantages and limitations of the pilot. Finally, we analyse whether a new way of co-creating future agendas for global change research could be established.

\section{Global change research in the Finnish context}

The conceptualisation of such a transdisciplinary research as the global change research in the Finnish context include understanding the concept of global change, without which planning detailed research is difficult. Furthermore, the desired types of its societal impact are at least as difficult to define. That is why the first steps of the pilot included the identification of global challenges affecting Finland (outputs from the first town hall meeting).

The first co-creation event attracted a wide group of participants who took part in the conceptualisation and co-creation of ideas for future events and activities of FEF. The event was structured so that after short motivational speeches, the main focus was on small group discussions based on the results of a pre-assignment that the participants were asked to answer prior to the meeting. A joint final panel discussion concluded the event.

The objective of the pre-assignment was to receive input on key priorities for future global change research in Finland for the discussions in the meeting. It was considered that a pre-assignment would give the participants a strong voice of the topics of the event already prior to the event and would motivate them to attend the event. The questions reflected the topic of the town hall meeting:

1. By global change, we refer to interlinked and largescale environmental and societal changes.

According to you, what are the most pressing challenges of global change affecting Finland?

2. The only extensive global change research initiative that has been funded by the Academy of Finland is FIGARE (1999-2002). What kind of global change research does Finland need and what are the best ways to organise and fund the research? 
3. How would you define the conditions to do global change research in Finland? What kind of limitations do researchers face now if they are interested in global change research?

4. Where are the most important 'gatekeepers', phenomena/groups in key positions to enable/ inhibit sustainable development in Finland?

Altogether, 37 participants completed the preassignment. The data was analysed by Future Earth Finland staff prior to the meeting and the key findings were summarised and handed out to the participants in the meeting. Figure 3 exemplifies some of the visualisation efforts made to present the results in an inspiring and intuitive way to the participants of the meeting.

The town hall meeting was regarded as a successful kick-off event for the pilot as it gathered over 60 participants. According to the feedback from the attendees of the meeting, the small group discussions had been the most productive and fruitful part of the meeting as they gave voice to various kinds of participants who were knowledgeable in the area of global change, but from different perspectives. The small discussion groups focusing each on a different topic (questions from the preassignments) were also seen as an inspiring working method because the discussions gave each participant a voice and allowed everybody to interact with each other, which was especially emphasised in the feedback material collected after the event as well as in the interviews.

The key outcome of the event was the identification of topical global change challenges from the Finnish perspective. Especially, future conditions of the Baltic Sea (e.g. storms, coastal erosion, future ice-free Baltic Sea, phosphorus cycle) and the challenge to find economically viable solutions for its management came forth in the discussions. It was also recognised that Finland is lagging behind in the transition towards renewable energy sources. Finland's target in 2015 to become carbon neutral by 2050 was considered to require substantial changes to energy policy and to production and transfer

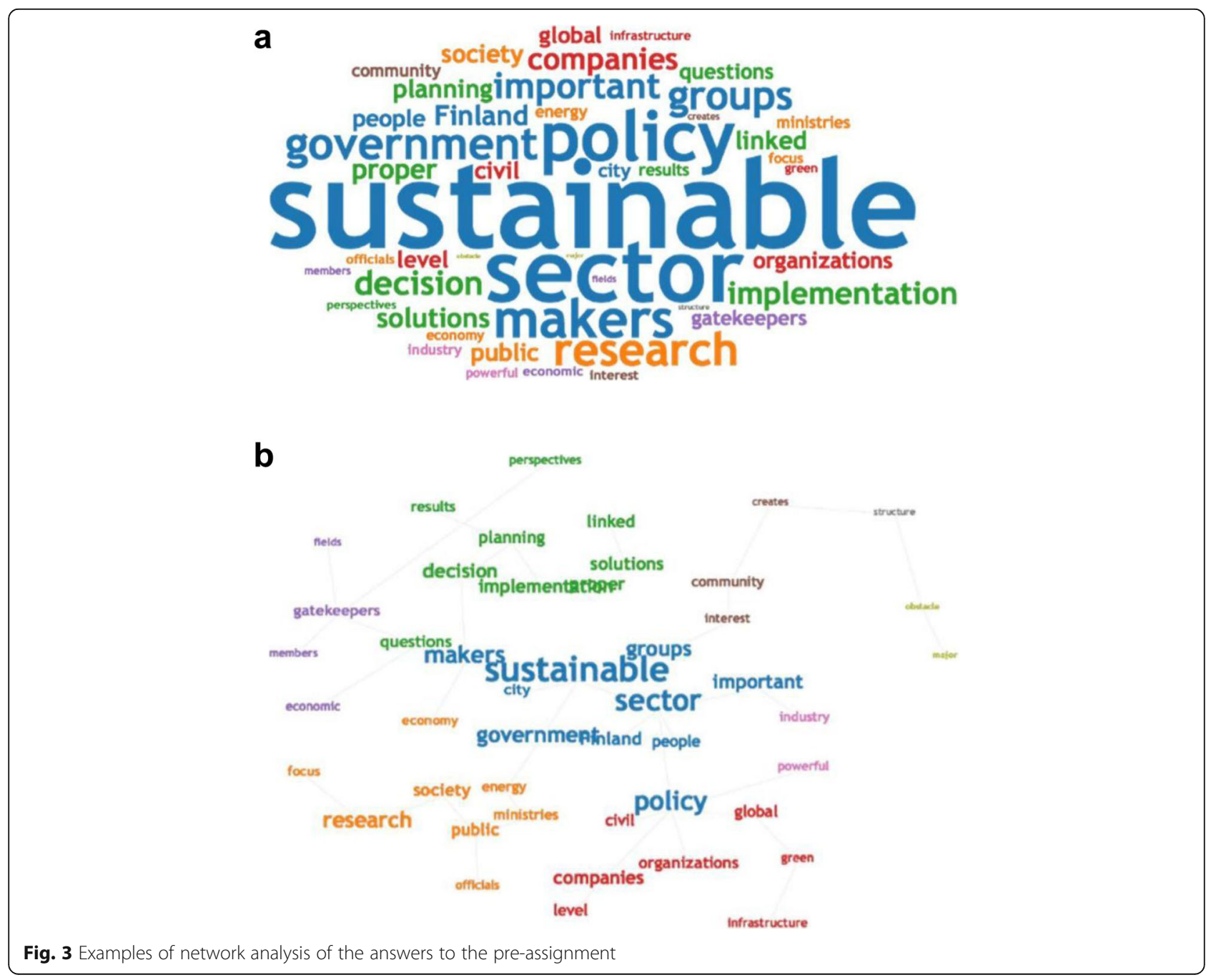


systems. This is linked to the strong urbanisation that is changing Finnish lifestyles, work, and mobility. A pressing question for the future in Finland is whether to develop the urban way of life further or take steps to keep the whole country populated as Finland has always been a very sparsely populated country. Other challenges recognised were related to the Arctic, sustainable consumption, aging societies, and transforming the aging Finnish society into one more sympathetic towards global immigration. Even though the composition of the participants included both natural and social scientists as well as policymakers and other stakeholders (see subsection 3.2.2.), there was some over-representation of environmental science experts, which can be reflected in the selection of the final research themes. However, there was quite a rich variety of expertise present, which suggests that the themes selected were supported by multiple perspectives and interests.

As a comparison, the Finnish National Commission on Sustainable Development defined the national challenges for the Finnish sustainable development in 2016. These were the securing of the welfare state in an aging society, the sustainability gap in public finances and the change in the structure of the economy, large climate gas emissions in relation to the population, securing biodiversity and sustainable, just and efficient use of natural resources $^{5}$. These topics clearly differ from those that the participants identified relevant for the Finnish context in global change research, although sustainability is the key issue in both.

The second large co-creation event on co-creating a sustainable city was organised in Tampere, the second largest urban area in Finland (after the metropolitan area). It gathered some 40 participants from different Finnish universities and universities of applied sciences (such as the University of Helsinki, the University of Tampere, and Tampere University of Applied Sciences) as well as from the private sector and municipalities. Similar to the first event, also this event was free of charge, open for all and advertised widely in the networks of the organisers. An open invitation was also published in the homepage of the FEF for both events. Participants also included representatives of research funders, public sector research institutes, nongovernmental organisations and citizens. This event built on the outcomes of the previous meeting and focused on the identified challenges posed by urbanisation. The final outcomes of the second large co-creation event were delivered to the Academy of Finland to act as a

\footnotetext{
${ }^{5}$ Suomi, jonka haluamme 2050-Kestävän kehityksen yhteiskuntasitoumus. Kestävän kehityksen toimikunta. https:// kestavakehitys.fi/ajankohtaista/artikkeli/-/asset_publisher/kestavankehityksen-toimikunta-paivitti-kestavan-kehityksen-

yhteiskuntasitoumuksen, accessed 28.11.2018.
}

basis for future research programmes in urban development in Finland (the top five topics listed below).

From fragmented planning to a holistic perspective: a shared, sustainable city

Decision-making in the city: co-production of ideas and information and transparent decision-making in long-term strategic planning

Optimising sustainable growth and carbon-neutrality

Sustainable and high-quality mobility; advancing public transportation, walking and cycling in the city

Decentralised renewable energy, energy efficiency and sustainable energy management

The large-scale events in Helsinki and in Tampere served as core events for a process that supported the conceptualisation of the phenomenon of global change research in Finland. Other smaller activities continued to further elaborate on the issue leading to collaborative research projects between different groups of actors. Other activities were carried out with diverse organisations and groups relevant for the topics at hand: the expert panels on sustainable development, funding agencies, think tanks, ministries, parliament, cities and municipalities, industry, non-governmental organisations and non-profit organisations. Individual MPs and journalists also participated in some of the events organised by FEF with the goal to enhance global change research.

\section{Developing new research and governance capacities}

In this section, we analyse how the pilot has created novel capacities to study global change. In many cocreation approaches, at the beginning of the process objectives are undefined, contrary to traditional innovation projects that aim at concrete, pre-defined goals. Moreover, the objectives can often change according to the interaction, emerging and changing needs, and aims of the participants.

At the beginning of the pilot, it was recognised that transdisciplinary research requires new kinds of practical and interpersonal expertise from researchers and other stakeholders as well as innovative institutional support structures. A key issue in terms of global change research highlighted in the pilot is that researchers do not typically know where to start looking for suitable societal partners for their research, how to approach and motivate them, and how to work with them in a participatory setting. Similarly, the non-academic stakeholders might not know how a scientific research project works and what an individual project could offer them. In addition, without deep understanding and familiarity with research in a certain field, stakeholders are not usually able to identify suitable research questions, to determine what they could offer a research project and which of their practical processes research could contribute to. 
Therefore, the larger and smaller events in the pilot focused on networking in order to help researchers and other stakeholders to develop their mutual understanding by clarifying the meaning of the terminology and drivers of the global change sustainability problems. The activities of the pilot have thus created network effects [20] in the sense of creating or expanding networks and producing trust among different stakeholders.

The researchers that participated in the science communication have had the opportunity to improve their interaction skills in the facilitated workshops and smallgroup discussions. The pilot shows that researchers benefit from training or educational programmes to support their participatory skills as they increase the mutual understanding and networking abilities of the participants. Importantly, our results indicate that both the researchers and other stakeholders have learned about the significance of transdisciplinarity in producing evidencebased solutions.

Evaluating the long-term impact of the initiative is at this stage difficult. However, we can already identify some advantages. These include:

Creating new mindsets and opportunities for participation and interaction in the field of global change research;

Allowing new networks and partnerships to be developed, creating new kind of knowledge-exchange between actors stemming from different backgrounds;

Developing opportunities for more inclusive meetings and discussions where each participant has an equal chance to speak out and a chance to exchange arguments between researchers in different academic fields, with other stakeholders and citizens;

Building research-based and practical competence in stakeholder and citizen engagement (also including notions of the significance of participants' comfort, and feeling of inclusion and participation);

Providing peer support in an academic environment where co-creation ideas are not always widely used or acknowledged.

The pilot was able to come out with new ideas and perspectives related to global change research, especially emphasising the beneficial inter- and multidisciplinary approach. On the other hand, we recognised that the training for the facilitators and moderators prior to the events was necessary for the success of the event, so the success of the activities depends also on the capacities of the organisers. Therefore, in the pilot, also the organisers have enhanced their capacities, which corresponds to the societal impact analysis of Wiek et al. [20] (see also [3]).

We identified problems that are typical to innovation platforms (e.g. [33, 34]) also in the global change research context. Cognitive barriers emerge from people having different cognitive backgrounds that can cause knowledge asymmetries and hinder effective communication, which is to be expected when the participants come from such various backgrounds and disciplines as in this case. Nevertheless, especially the student participants with less experience in research gave credit to the methods of engagement activities because the methods enabled also their opinion to be heard, which otherwise might not have been the case (pre-assignment, small group discussions, interactive wall). Motivational barriers arise from the actors' differing motivations or strategies that can make collaboration and trust difficult or even impossible if not dealt with in time, although this was not very visible in this pilot. Finally, identifying relevant parties is a contact barrier and it has shown to have a crucial role in the development of activities, which is why much emphasis was given to this aspect in the implementation of the pilot.

We relate one of the identified obstacles to the openended nature of this co-creation pilot. There was high uncertainty about the funding of activities by the side of FEF. Overall, securing adequate, long-term funding conditions is a challenge to multi-actor activities, which are not always recognised as a core activity at universities and research institutes. A broad enough financial resource base to cover the activities necessary for effective co-creation with stakeholders (e.g. [3]) would also be called for.

\section{Change towards a new way of co-creating global change research}

The continuity of the activities is in focus in this section. We examine whether a change towards a new way of co-creating global change research was established. Analysing the long-term continuity of the pilot of global change research is at this stage difficult. The network effects that we discussed in the previous section also contribute to the continuity of the activities introduced in the pilot. The networking effects have been considerable and the easiest to achieve. In every event, researchers and other stakeholders previously unfamiliar to one another have been able to meet and discuss issues important to both parties. Researchers have also made contacts with other researchers. In addition, stakeholders have given feedback that the facilitated events were extremely useful opportunities to reach out to other stakeholders and hear about their views, needs, and opportunities. The events have been a good step towards deepening the trust among the participants, which is a key in contributing towards a permanent change of cocreating research and continuity of action.

A permanent change may also ensue from an on-going process of working on the societal influence of universities and research aiming at co-creation of research together with key stakeholders from science policy in the 
government and research funding sectors. In fact, a visible outcome of the pilot activities contributing to its continuous impact is the inclusion of the BiodivERsA Stakeholder Engagement Handbook [35] in the list of recommended readings in the instructions of the new, Finnish funding instrument, Strategic Research ${ }^{6}$. In addition, a collaboration forum was built for the national expert panels on sustainable development, which means that there have been institutional changes in the Finnish research landscape. A prominent funding agency, Maj and Tor Nessling foundation ${ }^{7}$, has built a strong collaboration with FEF in the context of the pilot activities and promotes the use of co-creation as research methods in novel funded research projects.

Nevertheless, a number of practical problems emerged, related to continuity, such as the limited funding for transdisciplinary research and, as an even more pressing problem, the lack of a suitable academic career system that would support researchers to choose transdisciplinary approaches in their research. A number of researchers interested in pursuing societally relevant transdisciplinary research simply cannot do so because their main form of gaining merits is through publishing peer-reviewed, field-specific journal articles. Interdisciplinary, let alone transdisciplinary research is time- and resource-consuming, and the number of journals with expert evaluation system for such work is small.

\section{Discussion and conclusions}

We have presented a case study of a pilot on global change research as a forum to engage various actors in the co-creation of transdisciplinary research. The pilot aimed at addressing challenges emerging from global change in the context of the global north (see [3]). The main motivation in launching the pilot was the need to explore the concept of global change as a transdisciplinary issue and its significance and needed actions in Finland. The pilot also aimed at supporting new kind of transdisciplinary research to respond to the identified challenges. The implementation of the pilot of global change research was executed as a process consisting of several phases and events. At the preparation phase, the aim was to identify relevant partners, to build partnerships, and to commit them to the pilot. The first stage of activities was launching interactive events and activities. At each stage, stakeholder-researcher interaction methods were continuously evaluated and improved according to feedback from the participants in the pilot, the stakeholders and researchers.

\footnotetext{
${ }^{6}$ For more information on Strategic Research Council: https://www. aka.fi/en/strategic-research-funding/, accessed June 16, 2019

${ }^{7}$ For more information on Maj and Tor Nesslings Foundation: https:// www.nessling.fi/?lang=en, accessed June 16, 2019.
}

Clearly, neither co-creating future research agendas nor networking of actors are new ideas (e.g. [7]). In addition, building a sequence of events for a purpose is not new, either (e.g. [6]) these are comparable to the processes of transition arenas in sustainability transitions research (see e.g. [1, 36, 37]), for example. The novelty in this approach was reaching outside of the academic actors for multi-actor conceptualisation in global change and focusing on a very complex, transdisciplinary, diverse and a large-scale topic, which due to its nature has no single owner or advancer in the Finnish research landscape. Both the funders of research as creators of research agendas, as well as the researchers as creators of research projects in global change were on the focus of the activities, which was a novel co-creation approach.

The pilot was novel as it provided a concrete setting to engage stakeholders in designing and innovating societally relevant global change research. The main activities of the pilot included co-creation and co-design by users and producers involving also utilisers and enablers of global change research. The pilot also enabled the exploring and discovering emerging usages, behaviours, and market opportunities that could, in this case, be redefined as societal and user needs for research. Especially testing and developing co-production in practice supported piloting and in this case referring to best practices of co-creation in real-life co-operation in research projects: participatory methods and stakeholder interest. A clear benefit of the approach is its capacity to highlight multiple views [14].

The pilot has shown that agile processes to bring researchers and research users together in a permanent forum are effective in initiating action and in building research-based and practical competence and awareness in stakeholder and citizen engagement. They also provide peer support in an academic environment where co-creation ideas are not always widely acknowledged. The outcomes of the conceptualisation of what global change research means in a Nordic small country context, such as Finland, are also different from a national committee work for sustainable development, for instance. The co-creation of global change challenges for Finland highlighted research needs in relation to the Baltic Sea, the Arctic and urbanisation.

Limitations in engaging stakeholders in co-creation include the open-ended nature of the process. Therefore, it is highly sensitive to the availability of funding. Indeed, previous studies have found that one of the key challenges for conducting transdisciplinary sustainability research relates to funding (e.g. [16]). Because transdisciplinary and participatory efforts create additional costs, the financial resource base should be broad enough to cover them. For example, in order to ensure better inclusiveness, the workshops could have been organised 
simultaneously in other locations in Finland and digitally joined together as has been executed for example in a World Wide Views ${ }^{8}$-project. There were, however, not enough resources available for such an activity it this pilot.

In addition, transdisciplinary research requires a new kind of practical and interpersonal expertise from researchers and other stakeholders. Thus, both parties benefit from the enhancement of participatory skills. Transdisciplinary research also requires innovative institutional support structures, in particular, incentives and reward systems that allow researchers to engage in such research without the fear of losing in academic merits or career opportunities.

Another limitation in performing global change research is the current tendency in science to acquire profound expertise in a particular field of science, which often leads to a lack of an interdisciplinary perspective. Although scientific excellence in different fields lays the basis for interdisciplinary understanding, too deep a specialisation can lead to problems when people from different disciplines and from different backgrounds cannot properly communicate with each other and do not have sufficient incentives to do so. One way to enhance collaboration and shift towards true transdisciplinarity is through education. Adding transdisciplinary elements to bachelor and master training could help. In addition, doctoral students and early career researchers were recognised in the pilot as groups that could comparatively easily adopt more transdisciplinary thinking.

We conclude that the pilot of co-creation events as a concept is well suited for consideration of important societal questions. It provides co-creation spaces, which bring together different societal actors including producers, users, other stakeholders, citizens and enablers of research to co-design future research agendas and to network different actors to solve real-life societal questions in real-time (see e.g. [11]). Therefore, related to academic research of significant and societally critical topics [16], it offers a socially acceptable approach to contributing to the collaborative innovation in the design of transdisciplinary sustainability research. Nevertheless, while in the two main events much focus was given on the networking of researchers and on the interdisciplinary research, international collaboration, such as with the Smart Cities network, or the engagement with international global change networks was not highlighted in the discussions.

For future research, the pilot emphasised the importance of further studying and understanding the phenomenon of global change as a whole: global challenges are interlinked and 'everything affects everything

\footnotetext{
${ }^{8}$ For more information on World Wide Views: http://wwviews.org/
}

else'. Consequently, the question is how to achieve understanding on the various linkages and how to manage the complexity they form. Global change research clearly requires strong collaboration between natural and social sciences to reveal the connections between the different challenges as well as with humanities and engineering sciences, as well as collaboration with international networks. Global change research, however, is not well distinguished from other fields of science, such as futures studies, environmental sciences, climate sciences, and sociology. So, future research could focus on possibilities on how to better align humanities, natural and social sciences and engineering. In addition, global change research could be further conceptualised in terms of the other fields of science. A key question is whether global change research is already mature enough to be its own field of science and what would be the right balance between different sciences, particularly between natural and social sciences as global change research could focus also on socio-cultural and technoeconomic factors in addition to natural ones.

\section{Acknowledgements \\ The authors would like to thank the EU FP7 research support for funding the PE2020 project (GA no. 611826). The authors would also like to thank all citizens, stakeholders, policymakers and researchers who participated in the events. The authors would like to thank professor Eva Heiskanen for commenting on an early version of the manuscript as well as the participants of the ESEE2019 conference in Turku, Finland, in June 2019 for their valuable comments and insights to improve the manuscript.}

\section{Authors' contributions}

All authors contributed to the planning, writing and editing of the manuscript, as well as to the collection and analysis of the research data. All authors read and approved the final manuscript.

\section{Funding}

This research has been supported by the EU FP7 funded PE2020 project (GA no. 611826).

\section{Availability of data and materials}

The data used and analysed during the current study are publically available on the internet. Links for sites are included in the paper.

Ethics approval and consent to participate

Not applicable.

Consent for publication

Not applicable.

Competing interests

The authors declare that they have no competing interests.

\section{Author details}

'University of Helsinki, Unioninkatu 40 C, P.O.Box 24, 00014 Helsinki, Finland. ${ }^{2}$ Ministry of the Environment, Aleksanterinkatu 7, P.O. Box 35, Government 00023 Helsinki, Finland.

Received: 21 June 2019 Accepted: 27 January 2020

Published online: 24 February 2020

\section{References}

1. Kemp R, Loorbach D, Rotmans J (2007) Transition management as a model for managing processes of co-evolution towards sustainable development. 
Int J Sustain Dev World Ecol 14:78-91 https://doi.org/10.1080/ 13504500709469709

2. O'Brien M, Hartwig F, Schanes K et al (2014) Living within the safe operating space: a vision for a resource efficient Europe. Eur J Futur Res 2:1-11 https:// doi.org/10.1007/s40309-014-0048-3

3. Page GG, Wise RM, Lindenfeld L et al (2016) Co-designing transformation research: lessons learned from research on deliberate practices for transformation. Curr Opin Environ Sustain 20:86-92 https://doi.org/10.1016/j. cosust.2016.09.001

4. Tidd J, Bessant J, Pavitt K (2005) Managing innovation: integrating technological, market and organizational change. John Wiley \& Sons

5. Gudowsky N, Sotoudeh M, Capari L, Wilfing H (2017) Transdisciplinary forward-looking agenda setting for age-friendly, human centered cities. Futures 90:16-30 https://doi.org/10.1016/j.futures.2017.05.005

6. Repo P, Matschoss K (2018) Citizen visions for European futures - methodological considerations and implications. Eur J Futur Res 6: 1-8 https://doi.org/10.1186/s40309-018-0149-5

7. Rosa A, Gudowsky N, Warnke P (2018) But do they deliver ? Participatory agenda setting on the test bed. Eur J Futur Res 6:1-12 https://doi.org/10. 1186/s40309-018-0143-y

8. Moser C, Frick V, Blumer Y, et al (2016) Sports clubs as multipliers for energy-saving campaigns? Developing and evaluating a mobility intervention together with the city of Winterthur (Switzerland). 4th Eur Conf Behav Energy Effic 8-9

9. Mauser W, Klepper G, Rice M et al (2013) Transdisciplinary global change research: The co-creation of knowledge for sustainability. Curr Opin Environ Sustain 5:420-431 https://doi.org/10.1016/j.cosust.2013.07.001

10. Emmenegger R, Rowan R, Zuppinger-Dingley D et al (2017) Ontology and integrative research on Global Environmental Change: towards a critical GEC science. Curr Opin Environ Sustain 29:131-137 https://doi.org/10.1016/j. cosust.2018.02.001

11. Bulkeley H, Coenen L, Frantzeskaki N et al (2016) Urban living labs: governing urban sustainability transitions. Curr Opin Environ Sustain 22:1317 https://doi.org/10.1016/j.cosust.2017.02.003

12. Borquez R, Aldunce $P$, Adler C (2017) Resilience to climate change: from theory to practice through co-production of knowledge in Chile. Sustain Sci 12:163-176 https://doi.org/10.1007/s11625-016-0400-6

13. Funtowicz S, Ravetz J (2008) Post-Normal Science International Society for Ecological Economics. Encycl. Earth

14. Curșeu PL, Schruijer SG (2017) Stakeholder diversity and the comprehensiveness of sustainability decisions: the role of collaboration and conflict. Curr Opin Environ Sustain 28:114-120 https://doi.org/10.1016/j. cosust.2017.09.007

15. Repo P, Matschoss K (2019) Considering expert takeovers in citizen involvement processes. J Responsible Innov 6:119-142 https://doi.org/10. 1080/23299460.2019.1568145

16. Lang DJ, Wiek A, Bergmann M et al (2012) Transdisciplinary research in sustainability science: Practice, principles, and challenges. Sustain Sci 7:2543 https://doi.org/10.1007/s11625-011-0149-x

17. Adler C, Hirsch Hadorn G, Breu T et al (2018) Conceptualizing the transfer of knowledge across cases in transdisciplinary research. Sustain Sci 13:179-190 https://doi.org/10.1007/s11625-017-0444-2

18. Mader C (2013) Sustainability process assessment on transformative potentials: The Graz Model for Integrative Development. J Clean Prod 49: 54-63 https://doi.org/10.1016/j.jclepro.2012.08.028

19. Talwar S, Wiek A, Robinson J (2011) User engagement in sustainability research. Sci Public Policy 38:379-390 https://doi.org/10.3152/ $030234211 \times 12960315267615$

20. Wiek A, Talwar S, O'Shea M, Robinson J (2014) Toward a methodological scheme for capturing societal effects of participatory sustainability research. Res Eval 23:117-132 https://doi.org/10.1093/reseval/rvt031

21. Wiek A, Bernstein M, Foley RW et al (2015) Operationalising competencies in higher education for sustainable development. In: Barth M, Michelsen G, Rieckmann M, Thomas I (eds) Routledge Handbook of Higher Education for Sustainable Development. Routhledge, London, pp 241-260

22. Sarkki S, Niemelä J, Tinch $R$ et al (2014) Balancing credibility, relevance and legitimacy: A critical assessment of trade-offs in science-policy interfaces. Sci Public Policy 41:194-206 https://doi.org/10.1093/scipol/sct046

23. Yin RK (1994) Case study research: Design and Methods. First release. Thousand Oaks Sage 221-222. https://doi.org/10.1080/09500790.2011. 582317
24. Rask M, Mačiukaite-Žviniene S, Tauginiene L, et al (2018) Public Participation, Science and Society: Tools for Dynamic and Responsible Governance of Research and Innovation. Routledge, London

25. Krippendorff K (2018) Content analysis: An introduction to its methodology. Sage publications

26. Weber R (1990) Basic content analysis. Sage, Newbury Park

27. Suni T, Juhola S, Korhonen-Kurki K et al (2016) National Future Earth platforms as boundary organizations contributing to solutions-oriented global change research. Curr Opin Environ Sustain 23:63-68 https://doi.org/ 10.1016/j.cosust.2016.11.011

28. Rockström J (2016) Future earth. Science (80- ) 351:319. https://doi.org/10. 1126/science.aaf2138

29. Pietilä M, Matschoss K (2016) Pilot report on Living Lab of Global Change Research. Pilot report of the PE2020-project.

30. Gulbrandsen LH (2014) Dynamic governance interactions: Evolutionary effects of state responses to non-state certification programs. Regul Gov 8: 74-92 https://doi.org/10.1111/rego.12005

31. Smits R, Kuhlmann S (2005) The rise of systemic instruments in innovation policy. Int J Foresight Innov Policy 1:4-32 https://doi.org/10.1504/ijfip.2004. 004621

32. Parkinson J, Mansbridge J (2012) Deliberative systems: Deliberative democracy at the large scale. Cambridge University Press

33. Birrer FAJ (2001) Social science political counseling: the good, the bad and the enticed. Sci Public Policy 28:438-440 https://doi.org/10.4324/ 9781315100708-4

34. Dutilleul B, Birrer FAJ, Mensink W (2010) Analytical framework and methodology. Cent Eur J Public Policy 4:60-85 https://doi.org/10.1007/9783-319-66842-0_4

35. Durham E, Baker H, Smith M, et al (2014) The BiodivERsA Stakeholder Engagement Handbook. Paris

36. Frantzeskaki N, Loorbach D, Meadowcroft J (2012) Governing transitions to sustainability : Transition management as a governance approach towards pursuing sustainability. Int J Sustain Dev 15:19-36

37. Hyysalo S, Lukkarinen J, Kivimaa P, et al (2019) Developing Policy Pathways: Redesigning Transition Arenas for Mid-Range Planning. Sustain 1-22. https://doi.org/10.3390/su11020603

\section{Publisher's Note}

Springer Nature remains neutral with regard to jurisdictional claims in published maps and institutional affiliations.

\section{Submit your manuscript to a SpringerOpen ${ }^{\circ}$ journal and benefit from:}

- Convenient online submission

- Rigorous peer review

- Open access: articles freely available online

- High visibility within the field

- Retaining the copyright to your article

Submit your next manuscript at $>$ springeropen.com 